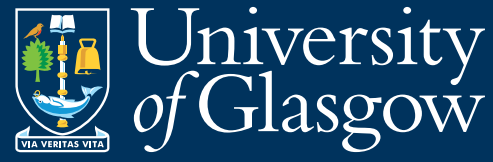

Adam Smith

Business School

WORKING

PAPER
SERIES

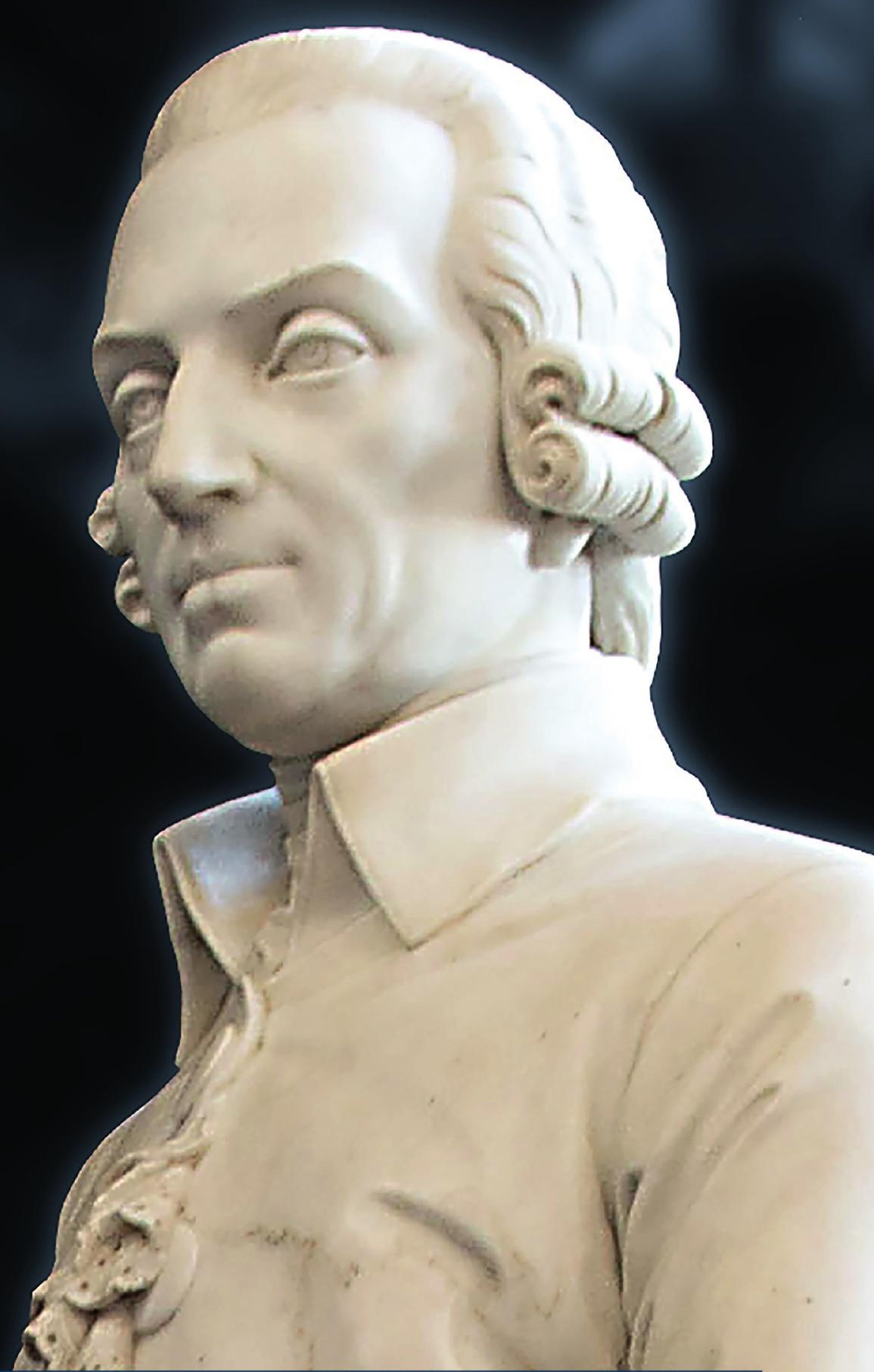

Management Practices and Takeover Decisions

Manthos D. Delis, Pantelis Kazakis and Constantin Zopounidis

Paper no. 2021-10 June 2021 


\title{
Management Practices and Takeover Decisions ${ }^{*}$
}

\author{
Manthos D. Delis \\ Montpellier Business School \\ University of Montpellier, Montpellier Research in Management \\ Pantelis Kazakis \\ Adam Smith Business School \\ University of Glasgow \\ Constantin Zopounidis \\ School of Production Engineering \& Management \\ Technical University of Crete
}

\footnotetext{
* Contact details: Delis is with Montpellier Business School, 2300 Avenue des Moulins, 34080 Montpellier, France, m.delis@montpellier-bs.com. Kazakis is with Adam Smith Business School, University of Glasgow, Gilbert Scott Building, West Quadrangle, Glasgow G12 8QQ, United Kingdom, pantelis.kazakis@glasgow.ac.uk. Zopounidis is with School of Production Engineering \& Management Technical, University of Crete, University Campus, 73100 Chania, Greece, E-mail: kostas@dpem.tuc.gr.
} 


\title{
Management Practices and Takeover Decisions
}

\begin{abstract}
Firms with good management practices optimize and synthesize human resources, leadership, and technical and conceptual skills to enhance firm value. In this paper, we examine the role of management practices in merger and acquisition (M\&A) decisions. M\&A decisions are among the most important corporate decisions, on which firms spend a lot of resources and managerial qualities. We estimate management practices as a latent variable using a structural equation production model and Bayesian techniques. The key advantage of the Bayesian approach is the use of informative priors from survey-based management estimation methods, which are however available for a limited number of firms. Subsequently, we examine the effect of management practices on takeover events. We first show that management practices, on average, increase the probability of M\&A deals. However, we also uncover a nonlinear U-shaped effect, which is consistent with the theoretical premise that poor management leads to many value-decreasing M\&A deals, whereas good management leads to many value-increasing M\&A deals.
\end{abstract}

Keywords: OR in corporate finance; Management practices; Bayesian methods; Mergers and acquisitions; Nonlinear models 


\section{Introduction}

Mergers and acquisitions (M\&As) are among the most important decisions of enterprises. A successful M\&A leads to improved productivity and performance, whereas an unsuccessful one leads to chronic operational problems and inferior performance (e.g., Arocena et al., 2020; Chen et al., 2017). Firms spend approximately USD 4 trillion every year in their effort to maximize the firm value via M\&As, but $70 \%$ of these events do not meet the goals originally set. A recent line of literature (Bai et al., 2021; Delis et al., 2021) emphasizes the importance of management practices on the performance of M\&As. However, the first key step on M\&A value creation is whether and how firms decide on M\&As.

Identifying the role of management practices as a determinant of M\&As is a significant, but still unexplored research question. Firms with good management practices are those that optimize three key characteristics: Human resource management and leadership, technical abilities including human and intellectual capital, and conceptual skills to develop ideas from abstract thoughts (Katz, 1974; Delis and Tsionas, 2018). Thus, we consider management practices as a general firm-wide concept that effectively encompasses the future position and strategy of the firm; this naturally includes M\&A decisions.

We propose that there exist both positive and negative forces in the potential relation between this general notion of good management practices and the probability of M\&A events, implying that the average effect of management practices on M\&As is ambiguous. On the positive side, firms with good management practices can better distinguish the value-enhancing M\&As from the value-decreasing M\&As, due to their superior technical abilities and conceptual skills. These firms also have the right human resources, leadership, and technical skills, to organize the new firm post-M\&A and smoothly transition to a valueenhancing environment. Thus, firms with good management practices have incentives to promote expansion via M\&As, and are thus more likely to participate in M\&As by scrutinizing the market and finding good deals.

On the other hand, some managers may have the mentality of empire building. Such managers acquire firms that do not add synergistic gains to the combined firm, possibly because they prefer growth over value, which might relate to their personal objectives (as opposed to the shareholders' objectives). In turn, such agency problems lead firms with low quality management practices to also pursue several M\&A deals. As management practices improve, but do not become superior, this potentially negative relation between management practices and M\&A deals weakens, because managers of average quality neither pursue their objectives (thus leading to bad outcomes), nor are they able to identify value-enhancing M\&A deals. Taken together, the positive and negative forces might imply a nonlinear U-shaped relation between management practices and M\&A deals. 
We examine this hypothesis by first estimating management practices, using a structural equation model and Bayesian techniques (Delis and Tsionas, 2018; Delis et al., 2020). We assume that management is a latent input of production that enters a firm's production function (the first equation of our model) alongside the observed capital and labor (Lucas, 1978; Bloom et al., 2017). The second equation of the model assumes that management is well-approximated by a sigmoid activation function that follows an artificial neural network process. This approach, which is unique to our paper, allows for a deep-learning process that works very well for gradient-based optimization problems with log-likelihood functions, such as those in our case. Within this approach, the role of priors becomes more important compared to the variables used to approximate management practices (as is the case in Delis and Tsionas, 2018, who use relatively uninformative priors).

We estimate our two-equation latent variable model using Bayesian analysis, which provides superior inferences in models with latent variables, especially when good priors are available. We obtain information on our priors from the World Management Survey, which estimates management practices using a state-of-the-art survey of a finite number of firms and reports data on the same variables we have used, to estimate our model. Delis and Tsionas (2018) and Delis et al. (2020) show that this approach produces estimates of management practices that fare particularly well in several validation exercises. For inference on our Bayesian estimates, we use Markov Chain Monte Carlo (MCMC), which we implement using the particle Gibbs sampler.

Our analysis covers a panel of about 40,000 firm-year observations over the period 1980-2016, including 15,261 M\&A deals. Using such a wide panel would not be an option without estimating management practices (i.e., relying on survey data). Our management practices index takes values between zero and one (with a mean value of 0.48 ) and approximately follows a normal distribution. The annual average of the index is fairly constant, which is intuitive because relative managerial skill does not significantly change over time. The cross-industry variation of our index is also small.

Subsequently, we examine how management practices affect the probability of M\&A deals using logit models. We find that management practices have, on average, a positive and statistically significant effect on the probability of M\&A deals. Economically, however, the effect is smaller than anticipated: a one standard deviation increase in our management practices index increases the probability of M\&As by approximately $0.55 \%$.

We mainly attribute the economically small effect to the potential nonlinearity in the relation between management practices and M\&A deals. Indeed, consistent with our theoretical contemplations on empire-building behavior and agency problems, we find a high probability of M\&A deals for low values of management practices. This relation is negative up to a value of management practices equal to 0.43 , which is between the first and the second quartile of our management practices index. Above this minimum, the 
relation turns positive, consistent with our theoretical prediction of more M\&A deals for firms with better management practices.

We delve deeper into this finding and examine if indeed M\&A success is the driving force behind the identified nonlinear effect. We assume that better management implies fewer value-destroying M\&As (those with negative cumulative abnormal returns) and more value-enhancing M\&As (those with positive cumulative abnormal returns). Consistent with this premise, we find a negative (positive) relation of management practices with the probability of takeover events that destroy (create) value, especially for management practices scores above the minimum value of 0.43 .

Our analysis and results bring together two strands of literature. The first is the operations research literature on management practices and its estimation. Demerjian et al. (2012) use a two-stage data envelopment analysis (DEA) method to decompose firm efficiency into management quality and the remainder efficiency component. Andreou et al. (2013) use an equivalent stochastic frontier approach. Delis and Tsionas (2018) and Delis et al. (2020), favor and validate a Bayesian approach that is similar to the one used by us, except for the equation predicting management practices (for which we use a neural network process).

The second strand of literature includes studies on the intersection between operations research and corporate finance. Most related to our analysis, Bai et al. (2021) show that firms with more specific, formal, frequent, and explicit (i.e., "structured") management practices acquire firms with less structured management practices. Delis et al. (2021), study the effect of management practices on M\&A success, instead of the probability of M\&A deals. Of course, several other studies in corporate finance examine the effect of other firm or macro characteristics on the probability of M\&A deals (Bai et al., 2021 cite the most recent literature).

The rest of the paper is structured as follows. Section 2 provides a definition of management practices using the management and OR literatures; this section also discusses our Bayesian approach. Section 3 analyzes the effect of management practices on M\&A decisions and discusses the empirical results. Section 4 concludes the paper.

\section{Management practices and their estimation}

\subsection{Defining management practices}

Management practices affect all dimensions of firm performance, and the literature proposes many approaches for its measurement (Tarí et al., 2007; Hietschold et al., 2014, Delis et al., 2020). We view management practices as a firm-wide concept following Katz (1974). Thus, the definition of management 
encompasses three general concepts. First, human resource management and leadership, which not only motivate employees, but also interact with different entrepreneurial forces to improve the position of the firm in the corporate world. Second, technical abilities, which account for the human and intellectual capital that managers at different echelons have about their respective roles. In practical terms, this reflects the decisions that increase firm value. Third, managers with higher conceptual skills are better at developing ideas from abstract thoughts, because such managers are more broad-minded and think about the future position of the firm among its competitors and consumers.

This definition characterizes a good manager from his/her ability to gather, allocate, and distribute resources and products efficiently, thus being able to increase firm value and the position of the firm in the eyes of its stakeholders (Pasiouras, 2013). Examples are when managerial decisions increase firm sales and revenue from using the same but better allocated inputs, and when competent managers identify or achieve lower debt premiums (Bonsall IV et al., 2017). Several studies show that such skills result in higher managerial compensation (e.g., Falato et al., 2015).

Recent literature on management practices, especially by Bloom et al. (2017), builds on early models of management, such as Lucas (1978), and shows that apart from labor and capital (including physical and financial capital, R\&D expenses, and land), management practices are an important factor of production and the one that completes the list. This theoretical literature shows that management practices explain large firm productivity differences and operate as a superior technology. Therefore, differences in management practices between the top and the bottom of the distribution of firms can generate large differences in performance. To this end, we treat management practices as a missing input of production, the one encompassing these general firm-specific traits.

Our definition of management practices and its representation as the missing link in the production process is also fully in line with the literature on total quality management (e.g., Prajogo and Sohal, 2006; Taríet al., 2007) and managerial ability (Demerjian et al., 2012; Koester et al., 2017; Delis and Tsionas, 2018). These studies also reflect the broad firm-level nature of management practices, including leadership, training, human resource management, information and analysis, supplier and process management, and continuous improvement. Notably, these are dynamic characteristics that can drastically change with time, although they also present large cross-firm heterogeneity.

\subsection{Measuring management practices}

We focus on measures of management practices that explicitly reflect the literature's broad definition at the firm-level. Part of this literature uses production functions and frontier techniques (data envelopment analysis or stochastic frontiers). Demerjian et al. (2012) introduce a measure of managerial ability, by 
measuring the managers' efficiency compared to that of their industry peers. They assume that management is the only missing input of production - our analysis follows the same premise. To measure efficiency, they use standard data envelopment analysis (DEA), differentiating between the elements of efficiency that can be directly affected by managers and those that are outside the management's reach. A manager is assumed to be more efficient when she is better able to transform corporate resources to revenues.

Several studies have utilized the dataset provided by Demerjian et al. (2012) either as a key explanatory variable, or a control in their analysis. Among others, Bonsall IV et al. (2017) look at how managerial ability correlates with credit risk assessment; Chang et al. (2016) study how the risk of financial distress affects the compensation of new CEOs; and Koester et al. (2017) study the relation between managerial ability and corporate tax avoidance.

Other research uses stochastic frontier analysis (SFA) instead of DEA. Andreou et al. (2013) use this model to estimate management practices and study the relation between managerial ability and firm performance. Bonin et al. (2005) study bank performance in transition countries, while Tabak and Tecles (2010) look at the Indian banking system. Finally, Sueyoshi (1994) uses this method to measure performance in public telecommunications. A good reference comparing the SFA and DEA methods is Wu et al. (2011).

Other studies in operations management and economics rely on survey data to measure management practices. A naturally related concept in the operations management literature is total quality management (TQM), which has emerged as a key tool to help firms boost their activities and performance (Powell, 1995). The TQM literature argues that higher-quality management translates into lower costs, increases productivity, and eventually yields higher competitiveness for a firm (Deming, 1982; Hendricks and Singhal, 1997; 2001). The role of well-designed surveys is the key to the proper measurement of TQM instruments (e.g., Flynn et al., 1994, Prybutok and Ramasesh, 2005, Tarí et al., 2007). Similarly, a prominent example in the economics literature is that of Bloom and Van Reenen (2007 \& 2010) and their World Management Survey (WMS). Using surveys with well-defined questions is the "holy grail;" however, it is almost impossible to generate large firm-year datasets from such surveys (this would naturally be too complicated and expensive, as there are issues of sample selection and representativeness). Another issue is that the questions used to infer management practices may not be appropriate in all circumstances and all types of firms. This may add measurement error.

We opt for a measure of management practices that combines both theoretical and empirical advantages. Delis and Tsionas (2018) and Delis et al. (2020), specifically propose a model with management as a latent input of production, estimated with Bayesian techniques. From a theoretical viewpoint and consistent with the seminal literature discussed above, management is the sole missing input of production (Lucas, 1978; Demerjian et al., 2012; Andreou et al., 2013; Bloom et al., 2017). Further, the stochastic 
nature of this model effectively separates management from other unobserved components of the production process; this is the key advantage of this model over DEA. From an empirical viewpoint, the key advantage of this technique is that it only requires widely available accounting data on inputs and outputs. As most firms provide such information, we can measure management practices for a far larger number of firms, compared to the survey methods. In addition, Delis and Tsionas (2018) validate their measure against the state-of-the-art measures of management practices in the World Management Survey and with Monte Carlo simulation techniques. They show that their measure performs better than the previous mathematical methods measuring management practices, and is more direct in capturing the actual management practices and not the other latent characteristics of the firm, such as firm culture.

The model includes the following production function:

$$
\begin{aligned}
\ln \left(q_{i t}\right)= & \beta_{0}+\beta_{k} \ln \left(k_{i t}\right)+\beta_{l} \ln \left(l_{i t}\right)+\beta_{m} \ln \left(m_{i t}\right)+\frac{1}{2} \beta_{k k} \ln \left(k_{i t}\right)^{2}+\frac{1}{2} \beta_{l l} \ln \left(l_{i t}\right)^{2}+\frac{1}{2} \beta_{m m} \ln \left(m_{i t}\right)^{2}+ \\
& \beta_{k l} \ln \left(k_{i t}\right) \ln \left(l_{i t}\right)+\beta_{k m} \ln \left(\mathrm{k}_{\mathrm{it}}\right) \ln \left(m_{i t}\right)+\beta_{l m} \ln \left(l_{i t}\right) \ln \left(m_{i t}\right)+u_{i t}
\end{aligned}
$$

In equation $1, q$ denotes the output of firm $i$ in year $t ; k, l$, and $m$, denote capital, labor, and management (the inputs of the production function), and $u$ is an error term. We use a translog specification because of its flexibility and linearity in parameters (Greene, 2008).

Although all other variables are observed and can be measured, management is a latent variable. We measure $q, k$, and $l$ using standard Compustat entries for the period 1980-2016. We measure $q$ with the $\log$ of sales. For $k$ we use core capital (net property, plant, and equipment), but also the cost of inventory and net operating leases (all variables in $\operatorname{logs}$ ). For $l$ we use the number of employees. We provide thorough definitions in Table 1.

Table 1. Variable definitions for the estimation of management

\begin{tabular}{ll}
\hline \hline Variable & Description \\
Sales & Sales (log in millions of dollars) \\
& \\
Inputs & Net property, plant, and equipment (log in millions of dollars) \\
PPENT & Number of employees (log in thousands) \\
EMP & Cost of inventory (log in millions of dollars) \\
CINVT & Net operating leases (log in millions of dollars). We construct this as in Demerjian et al. (2012) \\
& and use firms' footnotes in Compustat to calculate the discounted present value of future (five \\
NOL & years) operating lease payments. The Compustat items for the five lease obligations are MRC1 - \\
& MRC5, and we use a discount rate of 10\% in accordance with previous studies. \\
\hline \hline
\end{tabular}

For management practices $m$, we assume: 
$m_{i t}=\sum_{g=1}^{G} \gamma_{g} \phi\left(a_{g}+x_{i t}^{\prime} \beta_{g}\right)+v_{i t, 2}, i=1, \ldots, n, t=1, \ldots, T$.

In equation $2, \phi(z)=\frac{1}{1+e^{-z}}, z \in \mathbb{R}$,is a sigmoid activation function that follows an artificial neural network process with $G$ nodes. We choose a sigmoid function due to its good properties and fit in our model. First, our management practices measure takes values between zero and one. Second, a sigmoid function is differentiable and monotonic. Third, a sigmoid function works very well for gradient-based optimization problems with log-likelihood functions (see also Goodfellow et al., 2016), such as the ones in our case. Essentially, this approach allows for a deep learning process that places significant weight on the informative priors discussed below for the determination of $m$ in equation 2 vis-à-vis the variables in $x$. This is the key difference of our paper, when compared with that of Delis and Tsionas (2018).

Following Delis and Tsionas (2018), we assume that management practices in equation 2 are approximated by lagged values of all inputs and the current value of labor. Practically, we contend that when inputs are used in optimal quantities and allocated efficiently, management quality is higher. Therefore, the assumption here is that management practices lie in the optimal use of a pre-specified vector of inputs, to maximize an output variable. The word optimal, as in Delis et al. (2020), "refers to both the absolute and the relative input quantities." We also include the price of labor as an input following governance literature, which finds a positive correlation between ability and human capital (e.g., Custódio et al., 2013). Identification through input prices has a long tradition in the production economics literature (e.g., Nevo, 2001). In our case, we assume the labor market is fairly competitive so the price of labor can be a valid instrument (Ackerberg et al., 2006; Delis and Tsionas, 2018).

Eventually, equations 1 and 2 determine a structural equation model (SEM), with management as a latent variable. To estimate this model, we use Bayesian techniques, which are optimal in SEMs with latent variables (e.g., Kaplan and Depaoli, 2012; van de Schoot et al., 2014). This is because Bayesian analysis considers uncertainty by its nature and, using informative priors, can better approximate latent variables compared to the standard frequentist SEM estimation.

Scale parameters for the Bayesian estimation follow a proper prior of the form $p(\sigma) \propto \sigma^{-(\bar{n}+1)}$. $\exp \left(-\frac{\bar{q}}{2 \sigma^{2}}\right)$.We use the following prior for our parameters: $\alpha_{g}, \beta_{g}, \gamma_{g} \sim$ iid $N(0,1), \frac{\bar{q}}{\sigma_{2}^{2}} \sim \chi_{\bar{n}}^{2}$. We also assume that $\bar{n}=50$ and $\bar{q}=10$. This would mean that in a fictitious sample of size 50 (denoted be $\bar{n}$ ), $\sigma_{2}^{2}$ would be on average $1 / 5$. We do not randomly select these priors: we choose them based on the characteristics of the variables in the WMS database.

For inference, we use Markov Chain Monte Carlo (MCMC), and we implement it using particle Gibbs sampling, which increases efficiency (Gelfand et al., 1990; Andrieu et al., 2010). Specifically, the 
advantage of this algorithm is its ability to draw paths of the state variables in large blocks. This simulationbased algorithm approximates continuous and marginal distributions with discrete distributions (Creal, 2012). Then, the particle Gibbs sampler uses a discrete approximation to draw a single path for the latent or state variables. When the number of particles reaches infinity, the particle Gibbs sampler is practically drawing from the full conditional distribution.

The study by Creal and Tsay (2015) is a good source for this procedure. Assume that the posterior is $p\left(\theta, \lambda_{1: T} \mid \boldsymbol{y}_{1: T}\right)$, with $\lambda_{1: T}$ denoting any latent variable whose prior is $p\left(\lambda_{t} \mid \lambda_{t-1}, \theta\right)$. We use the particle Gibbs sampler to draw the structural parameters $\theta \mid \lambda_{1: T}, \boldsymbol{y}_{1: T}$ from the posterior conditional distributions. Assume that in an iteration process we get the value $\lambda_{1: T}^{(1)}$. We then apply a particle filtering procedure that consists of two phases. We describe the algorithm in each phase below.

First phase: forward filtering (see also Andrieu et al., 2010).

- Draw a proposal $\lambda_{i t}^{(m)}$ from an importance density $q\left(\lambda_{i t} \mid \lambda_{i, t-1}^{(m)}, \theta\right), m=2, \ldots, M$.

- Compute the importance weights:

$$
w_{i t}^{(m)}=\frac{p\left(y_{i t} ; \lambda_{i t}^{(m)}, \theta\right) p\left(\lambda_{i t}^{(m)} \mid \lambda_{i, t-1}^{(m)} \theta\right)}{q\left(\lambda_{i t} \mid \lambda_{i, t-1}^{(m)}, \theta\right)}, m=1, \ldots, M
$$

- Normalize the weights in the following manner: $\widetilde{w}_{i t}^{(m)}=\frac{w_{i t}^{(m)}}{\sum_{m^{\prime}=1}^{M} w_{i t}^{\left(m^{\prime}\right)}}, m=1, \ldots, M$.

- Do a particle resampling of $\left\{\lambda_{i t}^{(m)}, m=1, \ldots, M\right\}$ with probabilities $\left(\widetilde{w}_{i t}^{(m)}, m=1, \ldots, M\right)$.

The original PG sampler stores values for $t=1, \ldots, T$ and a trajectory is sampled based on the probabilities of the last iteration. There is, however, an improvement on the aforesaid algorithm of the particle Gibbs sampler proposed by Whiteley (2010). He suggests drawing the path of the latent variables from the particle approximation, following the backward filtering procedure of Godsill et al. (2004). This can be described as follows:

Second phase: backward filtering (Chopin and Singh, 2015; Godsill et al., 2004).

- $\quad$ At $t=T$ draw a particle $\lambda_{i T}^{*}=\lambda_{i T}^{(m)}$.

- Compute the backward weights: $\widetilde{w}_{t \mid T}^{(m)}=\frac{w_{t \mid T}^{(m)}}{\sum_{m^{\prime}=1}^{M} w_{t \mid T}^{(m /)}}, m=1, \ldots, M$.

- Draw a particle $\lambda_{i t}^{*}=\lambda_{i t}^{(m)}$ with probability $\widetilde{w}_{t \mid T}^{(m)}$.

Notice that following the process described above, $\lambda_{i, 1: T}^{*}=\left\{\lambda_{i 1}^{*}, \ldots, \lambda_{i T}^{*}\right\}$ is a draw from the full conditional distribution. The second step is a fast and efficient procedure, but still requires to select the importance density $q\left(\lambda_{i t} \mid \lambda_{i, t-1}, \theta\right)$. Herein, we use the following importance density: $\lambda_{i t}=\alpha_{i t}+$ $\sum_{p=1}^{P} b_{i t} \lambda_{i, t-1}^{p}+h_{i t} \xi_{i t}$, with $\xi_{i t}$ following a Student-t distribution with five degrees of freedom. For $\lambda_{i, t-1}$ 
we use polynomials of order $P$.We choose polynomials because they are easier when dealing with approximations of probability density functions (see among others Eubank and Speckman, 1990; Badinelli, 1996). In the burn-in phase, we choose the parameters $\alpha_{i t}, b_{i t}$, and $h_{i t}$. Here we assume $P=1$ and $P=2$.

We do this because we prefer to have the weights $\left(w_{i t}^{(m)}, \widetilde{w}_{t \mid T}^{(m)}\right)$ close to a uniform distribution. Importantly, Chopin and Singh (2015) show that the sampler is uniformly ergodic and that backward sampling is more efficient asymptotically. Importantly, even in cases where the state vector is large, we can still recover the full conditional distribution.

According to Geweke (1992), the main problem of the Gibbs sampler is that the sequences produced are neither independent nor identically distributed. The author introduces a method to deal with this problem, which is computationally efficient and provides the convergence criteria (converge diagnostics). In practical terms, one has to compare the last half of the chain that has converged, with a smaller interval of the chain in the beginning, utilizing the spectral density estimation. In our study, the Gibbs sampler runs for 150,000 iterations, with the first 50,000 being burnt-in to avoid any start-up effects. Convergence is achieved and verified via Geweke's (1992) criterion and autocorrelation in MCMC never exceeds 0.4 in our setting.

We report estimation results in both numerical and graphical forms. We first report the distributional characteristics of the measure in Table 2 . The variable takes values from 0 to 1 . The bottom $5 \%$ has a value of 0.31 , while the top $5 \%$ a value of 0.66 . The cases where the management practices measure takes values above 0.75 are rare. With regard to the properties of the density function, we see that the skewness is small and kurtosis is around three, which implies that the distribution of the management scores resembles a normal distribution. Figure 1a shows this density.

Table 2. Distributional characteristics of the management practices measure

\begin{tabular}{|c|c|c|c|c|}
\hline & Percentiles & "Smallest & & \\
\hline $1 \%$ & 0.23 & 0 & & \\
\hline $5 \%$ & 0.31 & 0.02 & & \\
\hline $10 \%$ & 0.35 & 0.06 & Mean & 0.48 \\
\hline $25 \%$ & 0.41 & 0.06 & Std. Dev. & 0.11 \\
\hline $50 \%$ & 0.48 & Largest & Variance & 0.01 \\
\hline $75 \%$ & 0.56 & 0.93 & Skewness & 0.03 \\
\hline $90 \%$ & 0.62 & 0.94 & Kurtosis & 3.01 \\
\hline $95 \%$ & 0.66 & 0.95 & & \\
\hline $99 \%$ & 0.74 & 1 & & \\
\hline
\end{tabular}

Figure $1 \mathrm{~b}$ presents the average values of the management practices score over time. Our premise is that management practices must be relatively stable over time and the reason for this is that economic cycles do not determine managerial ability per se. In general, we find that this is the case. We observe some 
extreme values, such as the peak in 2000 and a trough in 2011, but the fluctuations are in fact statistically insignificant (the scale of the $y$-axis is small).

Figures $1 \mathrm{c}$ to $1 \mathrm{f}$ present estimates for different Fama-French industries. Figure 1c shows their mean values, which have a small and statistically insignificant range (from 0.4815 for nondurables to 0.4875 for telephone and TV). Interquartile differences (top $25 \%$ vs. bottom $25 \%$ ) show a larger difference for durables and the smallest for utilities. This means that managers in the durables sector are expected to have a larger heterogeneity in terms of their abilities compared to those in the utilities or finance sectors. In terms of extreme values, we find that nondurables along with healthcare have the highest scores, while the manufacturing and business equipment sectors have the lowest scores. The results are intuitive; according to Murphy and Zabojnik (2007) and Falato et al. (2015), managers mainly increase their salary through external hires rather than internal promotions. Thus, managers with higher human capital may choose to work in more lucrative sectors to increase their wealth. To this end, lucrative sectors, such as utilities or finance will have a lower heterogeneity in terms of managerial quality.

\section{Figure 1. Graphical illustration of management practices' scores}

Figure 1a shows the distribution of the management practices score. Figure $1 \mathrm{~b}$ shows annual mean values. Figures $1 \mathrm{c}$ to $1 \mathrm{f}$ show mean, interquartile difference, maximum, and minimum values of the management practices score for Fama-French industries (12 categories).

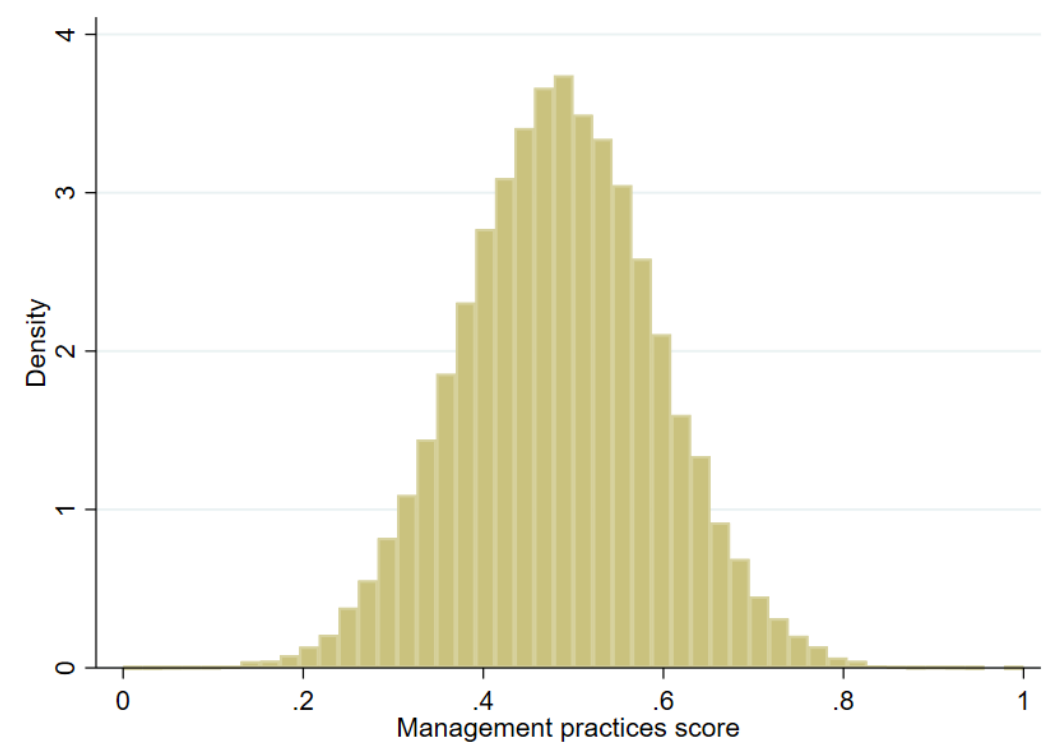

Figure 1a 


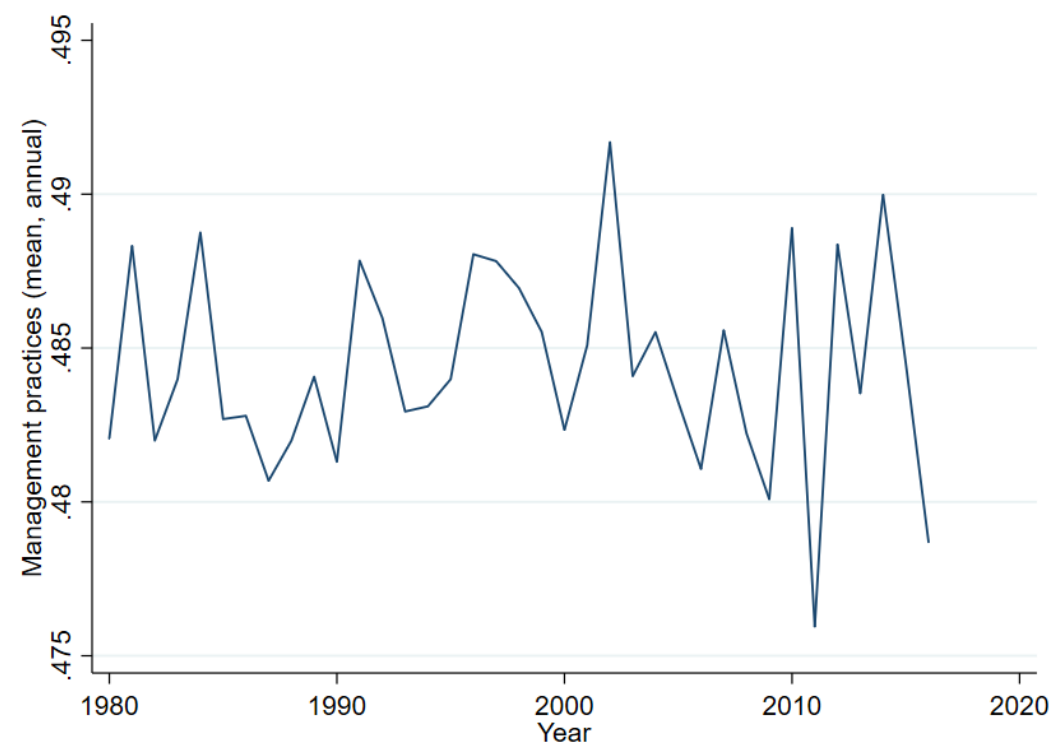

Figure 1b

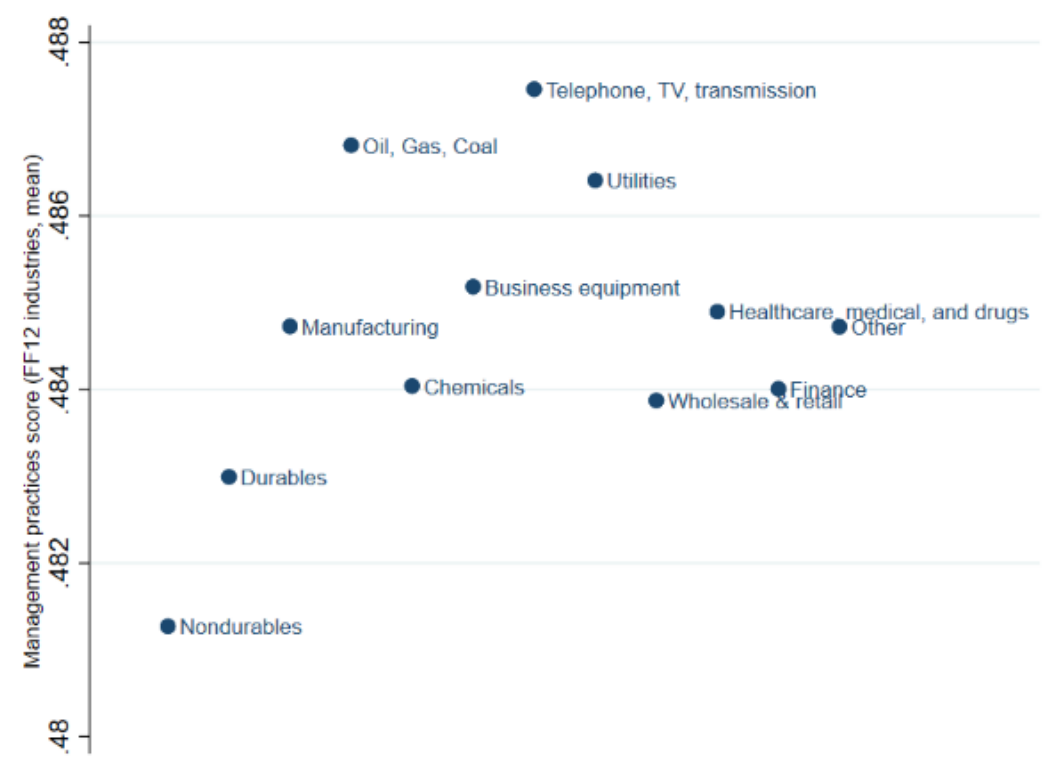

Figure 1c 


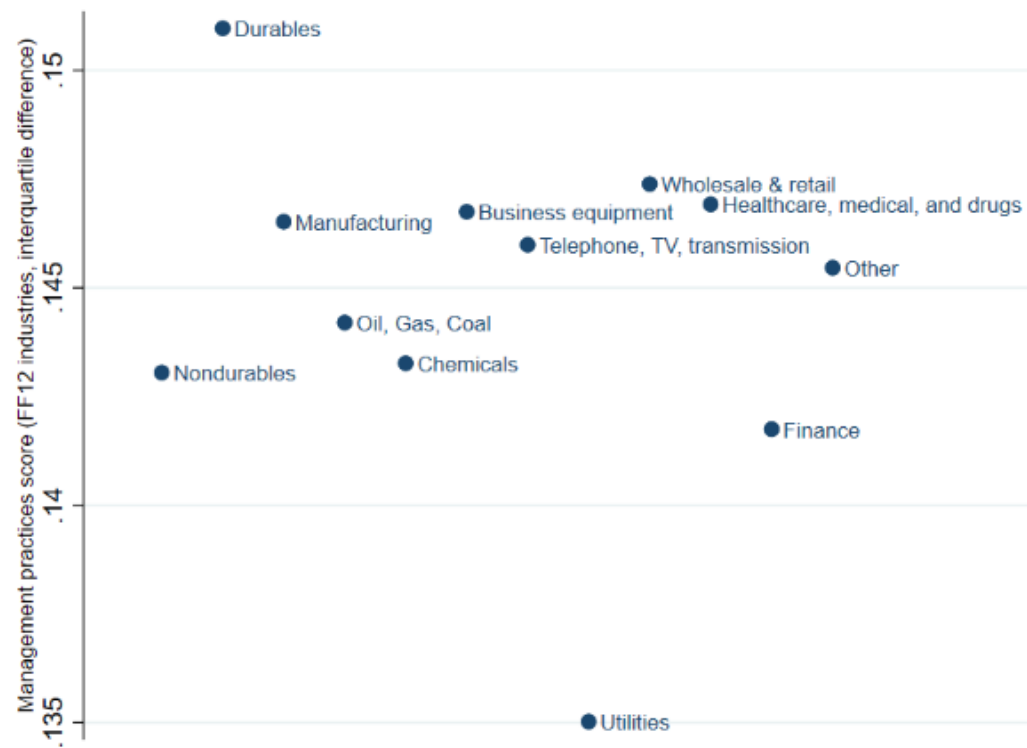

Figure 1d

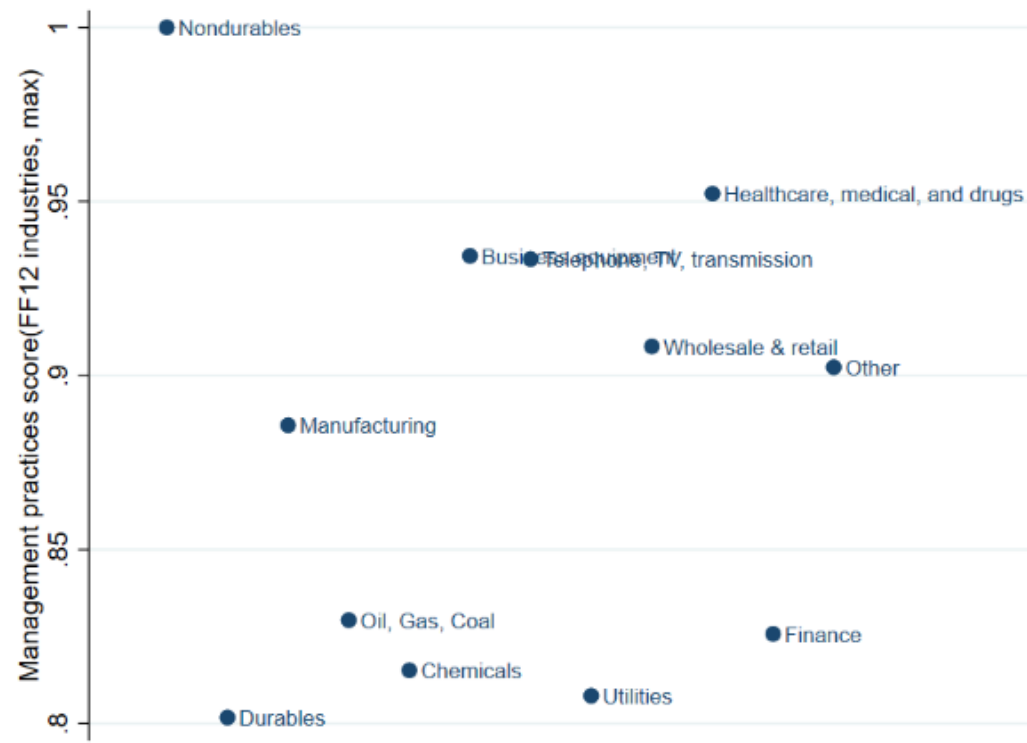

Figure 1e 


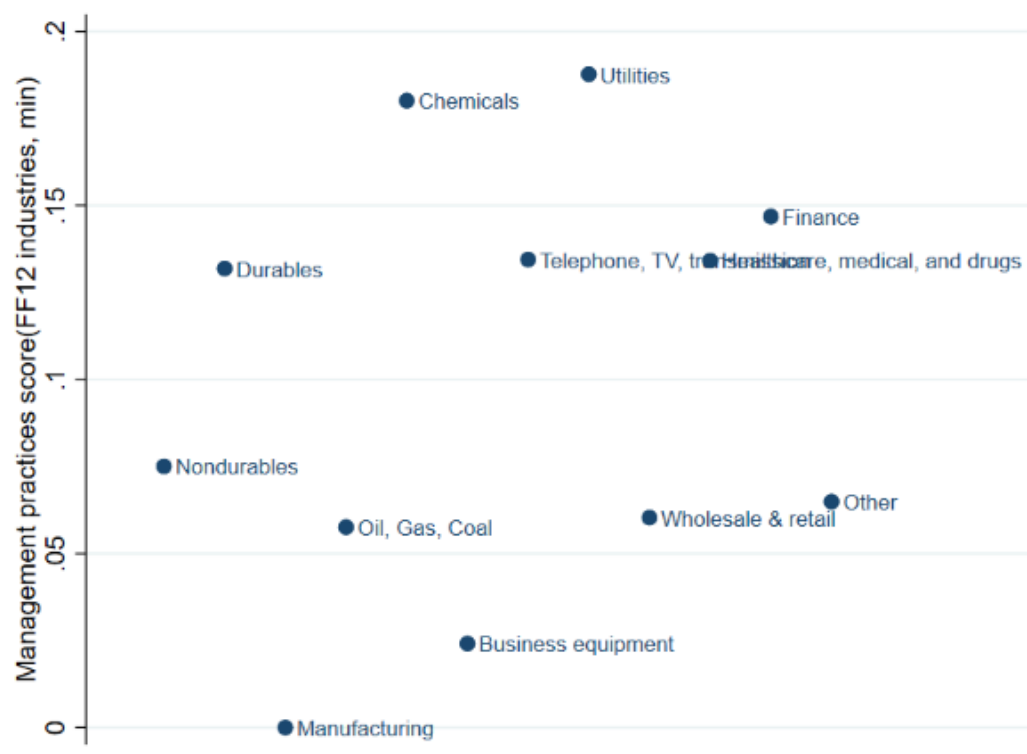

Figure 1f

\section{Management practices predicting M\&A decisions}

\subsection{M\&A sample and empirical model}

To construct the M\&A sample, we follow the standard filters described in Fuller et al. (2002) and used in many other studies that predict M\&A decisions. Specifically, (i) the acquiring company has to be a U.S. publicly listed corporation, and the target can be either a public, private, or subsidiary U.S. company; (ii) the acquisition must be complete; (iii) the acquirer must own less than $50 \%$ of the target company before the acquisition, although it wholly owns it afterward; (iv) the transaction is at least $1 \%$ of the acquiring company's market capitalization 11 days before the announcement and it is more that $\$ 1$ million; and finally, (v) we drop all deals that occur on the same day for the same acquirer.

Following the above filtering process, we find 15,261 takeover events for the period 1980-2016. The number of observations is larger because we use a firm-year panel (there are years without events). We end up with a panel of about 40,000 firm-year observations. Table 3 defines the variables used in our M\&A analysis and provides their sources. We report the relevant summary statistics in Table 4.

Table 3. Variable definitions and sources for the M\&A sample

The table defines the variables used in the M\&A empirical analysis. The source for the M\&A variables is Thomson One Banker. The source for the firm characteristics is Compustat. For ease of replicability, we include the Compustat codes in parentheses. Variable Description

M\&A event An indicator variable that takes value one if a firm has announced at least one M\&A event in a specific year. 
Frequent acquirer

Number of annual events

Log assets

Leverage

PPE

Taxes

ROA

Intangibles

Cash

Tobin's q

Stock return

Net profit margin

$\mathrm{MB}$

Demerjian et al. score
An indicator variable that takes value one if a firm has acquired at least five firms within a period of three years.

The total number of M\&A events in a specific year.

Firm assets (Compustat item AT) in logs.

Firm leverage. This is calculated as (DLC + DLTT)/AT.

Property, plant, and equipment (scaled). This variable is calculated as PPENT/AT.

Amount of taxes paid by a firm. This variable is calculated as TXT/PI.

Earnings before interest and taxes divided by total assets. This variable is calculated as EBIT/AT.

Firm intangibles (scaled). This variable is calculated as INTAN/AT.

Cash and short-term investments. This variable is calculated as CHE/AT.

This variable denotes the Tobin's q for a firm. It is calculated as (AT + CSHO*PRCC_F CEQ)/AT.

This variable denotes the stock return of a firm. It is calculated as:

$\left(\operatorname{PRCC} \_\mathrm{F}(\mathrm{t}) / \operatorname{AJEX}(\mathrm{t})+\operatorname{DVPSX} \mathrm{F}(\mathrm{t}) / \operatorname{AJEX}(\mathrm{t})\right) /\left(\mathrm{PRCC} \_\mathrm{F}(\mathrm{t}-1) / \operatorname{AJEX}(\mathrm{t}-1)\right)$.

This variable measures a firm's net profit margin and is calculated as NI/SALE.

This variable denotes the market-to-book ratio. It is calculated as CSHO*PRCC_F/CEQ.

This variable uses the management practices score provided by Peter Demerjian. The link with the data is the following: https://peterdemerjian.weebly.com/managerialability.html

Table 4. Summary statistics

\begin{tabular}{lcccccccc}
\hline \hline & Obs. & Mean & St. dev. & Min. & p25 & Median & p75 & Max. \\
\hline Sales & 47,188 & 5.750 & 2.122 & -6.908 & 4.349 & 5.724 & 7.159 & 13.089 \\
PPENT & 47,188 & 3.996 & 2.446 & -6.215 & 2.295 & 3.926 & 5.680 & 12.146 \\
EMP & 47,188 & 1.669 & 1.454 & 0.001 & 0.412 & 1.277 & 2.587 & 8.434 \\
CINVT & 47,188 & 3.516 & 2.556 & 0.000 & 1.132 & 3.639 & 5.440 & 11.775 \\
NOL & 47,188 & 3.247 & 1.919 & -0.219 & 1.755 & 3.112 & 4.552 & 10.177 \\
Management practices & 47,188 & 0.484 & 0.109 & 0.000 & 0.411 & 0.485 & 0.558 & 1.000 \\
Demerjian et al. score & 41,962 & 0.309 & 0.152 & 0.004 & 0.225 & 0.271 & 0.349 & 1.000 \\
M\&A event & 47,188 & 0.171 & 0.376 & 0.000 & 0.000 & 0.000 & 0.000 & 1.000 \\
Frequent acquirer & 8,722 & 0.196 & 0.397 & 0.000 & 0.000 & 0.000 & 0.000 & 1.000 \\
Number of annual events & 69,637 & 0.225 & 0.646 & 0.000 & 0.000 & 0.000 & 0.000 & 9.000 \\
Log assets & 47,188 & 5.641 & 2.128 & -2.235 & 4.161 & 5.576 & 7.075 & 11.882 \\
Leverage & 47,188 & 0.233 & 0.243 & 0.000 & 0.040 & 0.194 & 0.345 & 3.500 \\
PPE & 47,188 & 0.256 & 0.213 & 0.000 & 0.091 & 0.194 & 0.360 & 0.945 \\
Taxes & 47,188 & 0.253 & 0.317 & -1.352 & 0.107 & 0.340 & 0.395 & 1.310 \\
ROA & 47,188 & 0.025 & 0.277 & -7.371 & 0.002 & 0.065 & 0.124 & 0.421 \\
Intangibles & 47,188 & 0.140 & 0.176 & 0.000 & 0.000 & 0.066 & 0.217 & 0.735 \\
Cash & 47,188 & 0.169 & 0.198 & 0.000 & 0.026 & 0.087 & 0.244 & 0.970 \\
Tobin's q & 39,535 & 1.958 & 1.791 & 0.475 & 1.132 & 1.484 & 2.157 & 66.674 \\
Stock return & 39,535 & 1.205 & 0.662 & 0.098 & 0.827 & 1.094 & 1.408 & 4.810 \\
Net profit margin & 39,535 & -0.176 & 2.528 & -52.697 & 0.003 & 0.039 & 0.080 & 1.000 \\
MB & 39,535 & 2.831 & 4.913 & -30.351 & 1.238 & 1.997 & 3.331 & 43.642 \\
\hline \hline
\end{tabular}

To examine the effect of management practices on the probability of takeover events, we use the following logit model:

$$
P(Y=1 \mid \boldsymbol{X})=\frac{\exp \left(\beta^{T} \boldsymbol{X}\right)}{1+\exp \left(\beta^{T} \boldsymbol{X}\right)}
$$


In equation 3, $Y$ is the dependent variable that takes the value one if there is a takeover event and zero otherwise. $\boldsymbol{X}$ denotes the explanatory variables, including management practices. We use two more dependent variables, i.e., the probability of being a frequent acquirer and the number of acquisitions in a year (full definitions in Table 3). For the last case, we use a negative binomial model to account for the fact that we have large clusters with zero values when no takeover events occur; that is, we have overdispersion (Cameron and Trivedi, 2013; Statacorp, 2017). In brief, assume that for account variable $y_{j}$ the Poisson distribution takes the form $Y_{j} \sim \operatorname{Poisson}\left(\mu_{j}^{*}\right)$, where $\mu_{j}^{*}=\exp \left(\boldsymbol{x}_{\boldsymbol{j}} \boldsymbol{\beta}+\right.$ offset $\left._{j}+v_{j}\right)$. In a Poisson regression, offset is the variable that denotes the exposure period. We denote other covariates with $\boldsymbol{x}$. The

omitted variable, $v_{j}$, is such that $e^{v_{j}} \sim \operatorname{Gamma}\left(\frac{1}{a}, a\right)$. In this case, $\alpha$ is the overdispersion parameter. Here, we assume that $\alpha=\ln (a)$ and that $\ln \left(\alpha_{j}\right)=\mathbf{z}_{\boldsymbol{j}} \boldsymbol{\gamma}$, with $\mathbf{z}$ being the vector of covariates.

\subsection{Empirical results}

Table 5 reports marginal effects at means and t-statistics from the estimation of equation 3 . The first two regressions show results for the probability of the M\&A to occur, and Management practices carry a positive and statistically significant marginal effect. Albeit statistically significant, economically the effect is not particularly large: a one standard deviation increase in Management practices (equal to 0.11), increases the probability for an M\&A to occur by $0.55 \%$ (according to specification 2 ). We must note, however, that in the literature predicting M\&As, the explanatory variables have particularly low predictability, as is also evident in the low R-squared (e.g., Golubov et al., 2015; references therein). Moreover, the economically relatively weak effect might be due to the nonlinear U-shaped effect of management practices on M\&A deals.

In specifications 3 and 4 we use the probability of being a frequent acquirer as the dependent variable. The premise is that firms with better management will take up more value-enhancing M\&A opportunities and become frequent acquirers. Intuitively, we find results that are economically more significant: a one standard deviation increase in Management practices, increases the probability that a firm is a frequent acquirer by approximately $1 \%$ (according to specification 4). Moreover, in columns 5 and 6 , we use the Number of annual events as the dependent variable, and we estimate a negative binomial regression (as noted in section 3.1). The results in column 6 show that a one standard deviation increase in Management practices, increases the number of annual events by approximately 0.05 events, which corresponds to a $22 \%$ increase for the firm with an average Number of annual events (equal to 0.225 ). 
Table 5. Management practices and M\&As

The dependent variable in columns (1) and (2) is an indicator taking value one if an M\&A event is observed and zero otherwise. In columns (3) and (4) the dependent variable is an indicator taking value one when an acquiring firms has made at least five acquisitions within a three-year period. Finally, in columns (5) and (6) the dependent variable is the number of M\&A events for each firm in each year. Coefficients show marginal effects for the case of (panel) logit models. Standard errors for the panel logit use the observed information matrix when calculated, while they are clustered at the acquirer's level for the case of the logit and negative binomial models. We show t-statistics in parentheses. The logit model includes year and Fama-French 12 fixed effects. Table 1 shows the definitions of variables used to measure management scores. Table 3 shows the definitions of the control variables. Stars, ***, **, and *, indicate significance levels at the $1 \%, 5 \%$, and $10 \%$, respectively.

\begin{tabular}{|c|c|c|c|c|c|c|}
\hline \multirow[t]{2}{*}{$\begin{array}{l}\text { Dependent variable } \\
\text { Estimation method }\end{array}$} & \multicolumn{2}{|c|}{$\begin{array}{l}\text { M\&A event } \\
\text { Panel logit }\end{array}$} & \multicolumn{2}{|c|}{$\begin{array}{c}\text { Frequent acquirer } \\
\text { Logit } \\
\end{array}$} & \multicolumn{2}{|c|}{$\begin{array}{c}\text { Number of annual events } \\
\text { Negative binomial }\end{array}$} \\
\hline & (1) & (2) & (3) & (4) & $(5)$ & (6) \\
\hline Management practices & $\begin{array}{c}0.051 * * \\
(2.54)\end{array}$ & $\begin{array}{c}0.050 * * \\
(2.27)\end{array}$ & $\begin{array}{c}0.092 * * \\
(2.10)\end{array}$ & $\begin{array}{l}0.101 * * \\
(2.26)\end{array}$ & $\begin{array}{l}0.276^{* *} \\
(2.11)\end{array}$ & $\begin{array}{l}0.422 * * * \\
(2.85)\end{array}$ \\
\hline Log assets & $\begin{array}{c}0.035^{* * * *} \\
(14.06)\end{array}$ & $\begin{array}{c}0.026^{* * * *} \\
(9.36)\end{array}$ & $\begin{array}{l}0.004 \\
(0.82)\end{array}$ & $\begin{array}{l}0.004 \\
(0.79)\end{array}$ & $\begin{array}{l}0.104 * * * \\
(8.35)\end{array}$ & $\begin{array}{l}0.125 * * * \\
(9.50)\end{array}$ \\
\hline Leverage & $\begin{array}{c}-0.217 * * * \\
(-8.40)\end{array}$ & $\begin{array}{c}-0.260 * * * \\
(-7.53)\end{array}$ & $\begin{array}{l}0.057^{*} \\
(1.69)\end{array}$ & $\begin{array}{c}0.090^{* *} \\
(2.13)\end{array}$ & $\begin{array}{c}-0.382 * * * \\
(-4.04)\end{array}$ & $\begin{array}{c}-0.472 * * * \\
(-3.53)\end{array}$ \\
\hline PPE & $\begin{array}{l}-0.001 \\
(-0.03)\end{array}$ & $\begin{array}{l}0.016 \\
(0.38)\end{array}$ & $\begin{array}{c}0.147 * * * \\
(2.97)\end{array}$ & $\begin{array}{l}0.133 * * * \\
(2.65)\end{array}$ & $\begin{array}{l}0.604 * * * \\
(3.52)\end{array}$ & $\begin{array}{l}0.688^{* * *} \\
(4.44)\end{array}$ \\
\hline Taxes & $\begin{array}{l}0.010 \\
(1.17)\end{array}$ & $\begin{array}{l}0.004 \\
(0.42)\end{array}$ & $\begin{array}{l}-0.006 \\
(-0.25)\end{array}$ & $\begin{array}{l}0.003 \\
(0.12)\end{array}$ & $\begin{array}{l}0.058 \\
(0.66)\end{array}$ & $\begin{array}{l}0.028 \\
(0.28)\end{array}$ \\
\hline ROA & $\begin{array}{c}0.173^{* * * *} \\
(8.24)\end{array}$ & $\begin{array}{l}0.188 * * * \\
(6.59)\end{array}$ & $\begin{array}{l}0.058^{*} \\
(1.93)\end{array}$ & $\begin{array}{l}0.011 \\
(0.16)\end{array}$ & $\begin{array}{c}0.766^{* * *} \\
(4.82)\end{array}$ & $\begin{array}{l}0.745^{* * *} \\
(5.32)\end{array}$ \\
\hline Intangibles & $\begin{array}{l}-0.016 \\
(-0.54)\end{array}$ & $\begin{array}{l}0.043 \\
(1.26)\end{array}$ & $\begin{array}{l}0.383 * * * \\
(7.99)\end{array}$ & $\begin{array}{l}0.393 * * * \\
(7.68)\end{array}$ & $\begin{array}{l}1.683 * * * \\
(11.73)\end{array}$ & $\begin{array}{l}1.977 * * * \\
(12.73)\end{array}$ \\
\hline Cash & $\begin{array}{l}0.226^{* * * *} \\
(9.64)\end{array}$ & $\begin{array}{l}0.249 * * * \\
(8.04)\end{array}$ & $\begin{array}{l}0.031 \\
(0.64)\end{array}$ & $\begin{array}{l}0.011 \\
(0.19)\end{array}$ & $\begin{array}{l}1.051 * * * \\
(8.77)\end{array}$ & $\begin{array}{l}0.877 * * * \\
(6.06)\end{array}$ \\
\hline Tobin's q & & $\begin{array}{c}0.006^{* * * *} \\
(2.83)\end{array}$ & & $\begin{array}{l}0.003 \\
(0.95)\end{array}$ & & $\begin{array}{c}0.031 * * * \\
(2.94)\end{array}$ \\
\hline Stock return & & $\begin{array}{c}0.020 * * * \\
(5.04)\end{array}$ & & $\begin{array}{c}0.033 * * * \\
(4.48)\end{array}$ & & $\begin{array}{c}0.221 * * * \\
(8.63)\end{array}$ \\
\hline Net profit margin & & $\begin{array}{c}0.005^{* *} \\
(2.33)\end{array}$ & & $\begin{array}{l}0.018 \\
(1.15)\end{array}$ & & $\begin{array}{c}0.039 * * * \\
(3.89)\end{array}$ \\
\hline MB & & $\begin{array}{l}0.001 \\
(0.77)\end{array}$ & & $\begin{array}{l}-0.000 \\
(-0.14)\end{array}$ & & $\begin{array}{l}-0.005 \\
(-1.23)\end{array}$ \\
\hline Observations & 47,188 & 39,535 & 8,722 & 7,093 & 69,637 & 59,781 \\
\hline Pseudo $\mathrm{R}^{2}$ & 0.025 & 0.025 & 0.181 & 0.192 & 0.06 & 0.041 \\
\hline Log-likelihood & $-14,605.4$ & $-12,333.8$ & $-3,529.8$ & $-2,861.6$ & $-36,909.4$ & $-31,266.8$ \\
\hline
\end{tabular}

Given that our management practices measure represents a relatively new endeavor to measure managerial quality, we also examine how our findings fare against DEA methods. To this end, we use the Demerjian et al. (2012) measure of management quality, directly taken from Peter Demerjian's website. This method disentangles management quality from total efficiency by regressing the efficiency scores derived from a standard DEA model on several covariates that reflect firm characteristics which managers cannot affect. The DEA model is the following: 


$$
\begin{aligned}
\max _{v} \theta= & (\text { Sales }) \cdot\left(v_{1} \text { COGS }+v_{2} S G \& A+v_{3} P P E+v_{4} \text { OpsLease }+v_{5} R \& D+v_{6} \text { Goodwill }+\right. \\
& \left.v_{7} \text { OtherIntan }\right)^{-1}
\end{aligned}
$$

where $\theta$ denotes firm efficiency; COGS is the cost of inventory; $S G \& A$ advertising expenditure; $P P E$ property, plant, and equipment; OpsLease net operating leases; $R \& D$ net research and development; Goodwill purchased goodwill; and OtherIntan other intangible assets. The authors estimate DEA efficiency by Fama-French industries, aiming for firms to have similar business models. Next, they use Tobit regression:

Firm Efficiency $_{i}=\alpha+\beta_{1} \ln (\text { Total assets })_{i}+\beta_{2}$ Market Share $_{i}+\beta_{3} \mathbb{I}\left(\right.$ Free Cash Flow $\left._{i}>0\right)+$

$$
\begin{aligned}
& \beta_{4} \ln (\text { Age })_{i}+\beta_{5} \text { Business Segment Concentration }_{i}+ \\
& \beta_{6} \text { Foreign Currency Indicator }_{i}+\text { Year }_{i}+\epsilon_{i} .
\end{aligned}
$$

The residual from equation 5 constitutes their managerial ability score.

We report marginal effects and t-statistics in Table 6 . The results confirm those of Table 5, showing a positive and statistically significant effect of management practices on the probability of M\&As. ${ }^{1}$

Table 6. Management practices measured with DEA methods and M\&A events

This table replicates table 5's models shown in columns (1) and (2), but instead of using the measure of management practices calculated with Bayesian methods, we use the DEA-based Demerjian et al. (2012) scores. The estimation method is panel logit and we report marginal effects. The dependent variable is an indicator taking value one if an M\&A event is observed. Standard errors use the observed information matrix when calculated. We show t-statistics in parentheses. Table 1 shows the definitions of variables used to measure management scores. Table 3 shows the definitions of the control variables. Stars, ${ }^{* * *}, * *$, and $*$, indicate significance levels at the $1 \%, 5 \%$, and $10 \%$, respectively.

\begin{tabular}{lcc} 
& & \\
\hline & $(1)$ & $(2)$ \\
\hline Demerjian et al. score & $0.145^{* * *}$ & $0.109^{* * *}$
\end{tabular}

\footnotetext{
${ }^{1}$ Albeit the standard DEA measures yield qualitatively similar results, Delis and Tsionas (2018) and Delis et al. (2020) suggest that their correlation with the state-of-the-art measures of management practices provided in the WMS surveys for a limited number of firms is low. The reasons may be that the list of firm characteristics that managers cannot influence is non-exhaustive and many of these are unobserved (thus erroneously captured by the management score). Delis and Tsionas show that the Bayesian method used in this paper, compares significantly better to the WMS scores, while it is also validated by the formal Monte Carlo methods.
} 


\begin{tabular}{lcc} 
Controls & $\begin{array}{c}\text { Same as } \\
\text { column 1, } \\
\text { Table 5 }\end{array}$ & $\begin{array}{c}\text { Same as } \\
\text { column 2, } \\
\text { Table 5 }\end{array}$ \\
Observations & 41,962 & 35,207 \\
Pseudo R & 0.027 & 0.025 \\
Log-likelihood & $-13,029.5$ & $-11,029.6$ \\
$\chi^{2}$ & $734.92^{2 * * *}$ & $574.20^{* * *}$ \\
\hline
\end{tabular}

In our analysis so far, we have assumed that the relation between management practices and M\&As is linear. Although linear models allow for an easy interpretation of the findings, they may be less precise, and more advanced functional forms may be needed to achieve a better fit for the data (e.g., Chu and Zhang, 2013; Qin et al., 2007).

We also have theoretical reasons to believe that the relation between management practices and takeover events is nonlinear. Bruhn et al. (2010) argue that management practices pave the way for how firms utilize the inputs and marginal productivity. Specifically, firms with similar characteristics might present large heterogeneities regarding their performance, indicating that the latent characteristics (such as management practices) play a role. Soteriou and Zenios (1999) suggest that "the drivers of performance are many, and their interrelationships are highly complex and nonlinear." A potential theory that can explain this finding is that of the upper echelons, which suggests that organizational outcomes can be partially predicted by the characteristics of top managers running the firm (Hambrick and Mason, 1984; Miller, 1991). A more recent study supporting this theory is that of Gabaix and Landier (2008), who show that upper echelons in managerial quality might explain very large differences in CEO compensation.

The M\&A literature also consistently shows that not all takeover events are value-enhancing. Value destroying M\&As may be the result of an organization run by CEOs and managers with an empire-building mentality, indicating agency problems within the corporation (e.g., Gantchev et al., 2020). In such cases, the managerial objectives are generally inconsistent with the shareholders' objectives of firm-value maximization.

Based on the above, we expect a U-shaped relation between management practices and takeover events. The logic is the following. For low levels of management quality, we expect aggressive but valuedestroying M\&A firm behavior. This behavior is consistent with empire-building activities, which serve the managers' benefits and not the shareholders' objectives. As such, we expect regular takeover events for low scores of management practices. This relation should be negative up to an inflection point. That is, managers of higher but not superb quality participate less in takeover activities, because they understand the dangers of value-destroying M\&As. Beyond that inflection point, a quality management team is able to identify good investment opportunities and have a higher probability to target value-enhancing M\&As. 
We report results testing this hypothesis in Table 7, where we additionally include the squared term of management practices. Consistent with our hypothesis, we observe that the coefficient on the level term is negative and the coefficient on the squared term is positive; both are statistically significant. Setting $\frac{\partial M \& \text { event }}{\text { dManagement practices }}=0$ yields a minimum equal to 0.43 , at which point the effect of management practices on the M\&A event turns positive (based on the results of specification 2). We illustrate this Ushaped relation in Figure 2. Figure 2a precisely reflects the nonlinear U-shaped effect: the left-hand side shows a negative relation between management practices and an M\&A event for lower scores of management practices (approximately up to 0.43 ) and the right-hand side shows a positive relationship (from 0.43 onward).

Table 7. Nonlinearity in the management practices and $M \& A$ relation The dependent variable is an indicator taking value one if an M\&A event is observed and zero otherwise. The estimation method is panel logit. Coefficients show marginal effects. Standard errors use the observed information matrix when calculated. This table presents t-statistics in parentheses. Table 1 shows the definitions of variables used to measure management scores. Table 3 shows the definitions of the control variables. Stars, $* * *, * *$, and $*$, indicate significance levels at the $1 \%, 5 \%$, and $10 \%$, respectively.

\begin{tabular}{lcc}
\hline \hline & $(1)$ & $(2)$ \\
\hline Management practices & $-0.408^{* *}$ & $-0.484^{* *}$ \\
Management practices (squared) & $(-2.15)$ & $(-2.28)$ \\
& $0.485^{* *}$ & $0.562^{* *}$ \\
Log assets & $(2.47)$ & $(2.57)$ \\
& $0.043^{* * *}$ & $0.033^{* * *}$ \\
Leverage & $(11.12)$ & $(7.76)$ \\
& $-0.270^{* * *}$ & $-0.332^{* * *}$ \\
PPE & $(-8.49)$ & $(-8.15)$ \\
& -0.002 & 0.020 \\
Taxes & $(-0.04)$ & $(0.37)$ \\
& 0.012 & 0.0048 \\
ROA & $(1.17)$ & $(0.42)$ \\
& $0.215^{* * *}$ & $0.239^{* * *}$ \\
Intangibles & $(8.05)$ & $(6.86)$ \\
& -0.020 & 0.054 \\
Cash & $(-0.55)$ & $(1.25)$ \\
& $0.279^{* * *}$ & $0.317^{* * *}$ \\
Tobin's q & $(8.62)$ & $(7.73)$ \\
Stock return & & $0.007 * * *$ \\
& & $(2.82)$ \\
Net profit margin & & $0.026^{* * *}$ \\
MB & & $(5.00)$ \\
& & $0.006^{* *}$ \\
Observations & & $(2.36)$ \\
Log-likelihood & & 0.001 \\
\hline
\end{tabular}


To disentangle the two opposite effects, we next examine the role of the M\&A success. We expect that better management implies fewer M\&As that destroy value and more M\&As that create value. We use cumulative abnormal returns (CAR) with a one-day window, to categorize events into value-enhancing and value-destroying. To calculate cumulative abnormal returns, we first define abnormal returns as: $A R_{i t}=$ $R_{i t}-\mathbb{E}\left(R_{i t}\right)$, with $A R_{i t}$ being the abnormal returns for firm $i$ at time $t, R_{i t}$ the actual return for firm $i$ at time $t$, and $\mathbb{E}\left(R_{i t}\right)$ the expected return for firm $i$ at time $t$. The CAR is then calculated as $C A R\left(t_{1}, t_{2}\right)=$ $\sum_{t=T_{1}}^{T_{2}} A R_{i t}$. In our case $T_{1}=-1$ and $T_{2}=1$, with $\tau=0$ indicating the event date.

Figure $2 \mathrm{~b}$ shows a negative relation of management practices with the probability of takeover events that destroy value. This effect especially holds for scores of management practices above the optimal value of 0.43 , identified in the results of Table 7 (beyond this score, the slope of the negative relation becomes considerably steeper). In contrast, Figure $2 \mathrm{c}$ shows a positive relation between management practices and the probability of value-enhancing takeover events. Again, the positive effect gains considerable momentum (the elasticity of the regression line increases) for scores on management practices higher than 0.43 .

Figure 2. Graphical illustration of management practices' non-linearities on takeover events The top panel (Figure2a) shows graphically the effect of management practices non-linear effects on the probability of a merger event. The bottom panel from the left (Figure2b), shows the effect of management practices non-linear effects on the probability of a merger that destroys firm value (negative CAR), and the bottom panel from the right (Figure2c), shows the effect of management practices non-linear effect on the probability of a merger that creates firm value (positive CAR).

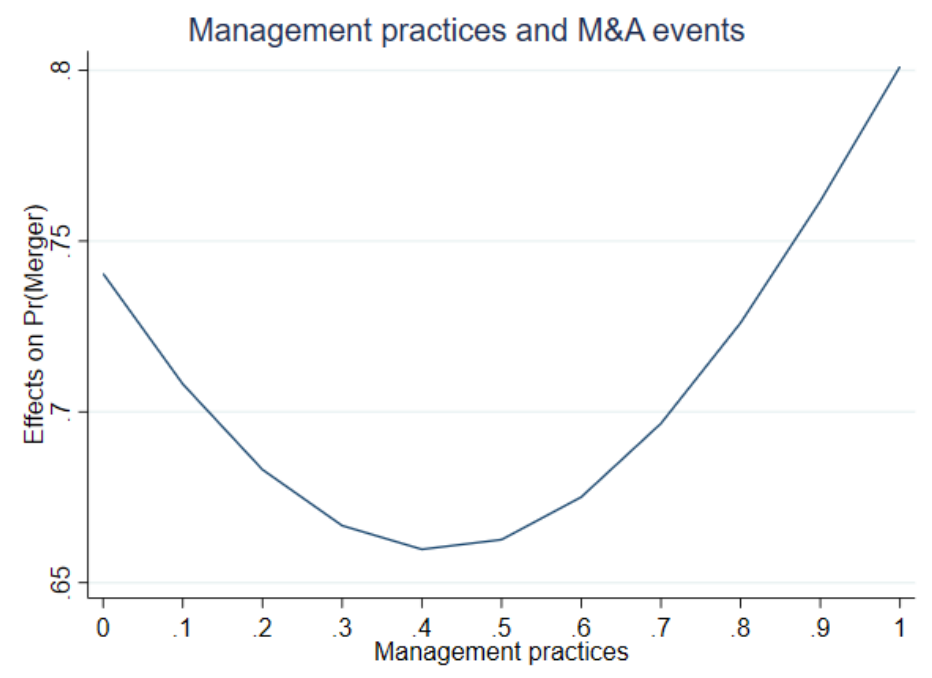

Figure 2a 


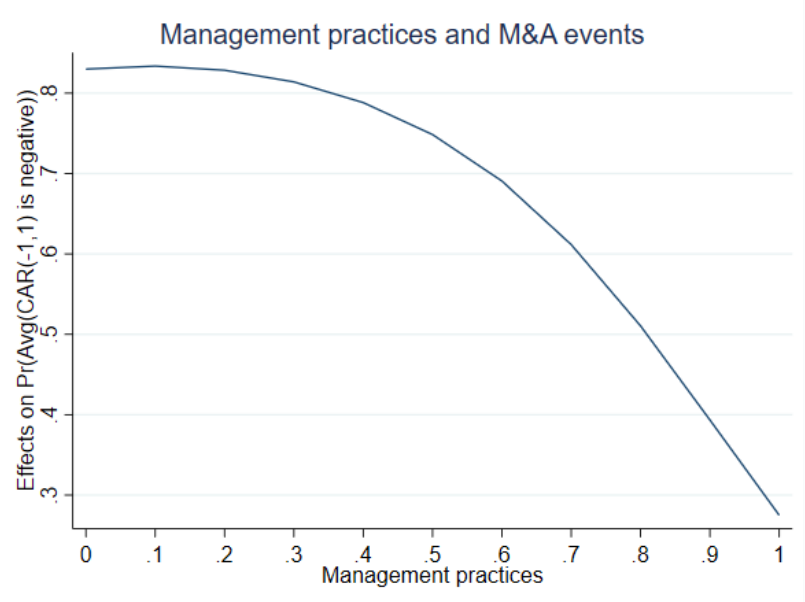

Figure $2 b$

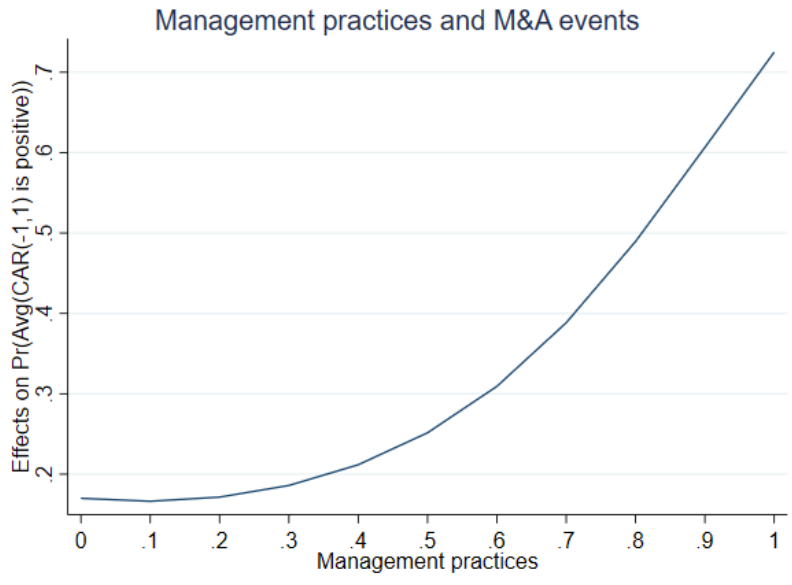

Figure 2c

\section{Conclusion}

Management practices and M\&A decisions theoretically go hand-in-hand. Firms with good management practices target value-enhancing M\&A deals, whereas firms with poor management practices target valuedecreasing M\&A deals. Both groups of firms might thus conduct more M\&A deals. In this study, we examine this hypothesis using more than 15,000 M\&A events over the period 1980-2016. We estimate management practices using a structural equation model, which includes management as a latent input of production. For the estimation method, we resort to a Bayesian approach that involves an artificial neural network process for the identification of management, and we obtain inferences from MCMC.

Our baseline results show that management practices have, on average, a positive effect on M\&A deals. Delving deeper into this relation and consistent with our theoretical arguments, we next identify a nonlinear U-shaped effect. Specifically, low levels of management practices are linked to a higher probability of M\&A deals that are, on average, value-decreasing, while high levels of management practices are linked to higher probability of M\&A deals that are value-increasing. Firms with management practices within the first and second quartiles have a lower probability to originate M\&As.

Our results have important implications, especially for the firms' shareholders. Shareholder screening of the quality of management practices is equally difficult and important, and our analysis suggests that management quality can be the key difference between value-enhancing and value-decreasing M\&As. Our analysis provides the first evidence on this important problem. Future work can further highlight the determinants of management practices, including corporate governance characteristics that point to specific agency problems, which in turn are linked to the probability and performance of M\&A deals. 


\section{References}

Ackerberg, D., Caves, K., \& Frazer, G. (2006). Structural identification of production functions, mimeo, UCLA Department of Economics.

Andreou, P. C., Ehrlich, D., \& Louca, C. (2013, January). Managerial ability and firm performance: Evidence from the global financial crisis. In European Financial Management Association, Annual Conference.

Andrieu, C., Doucet, A., \& Holenstein, R. (2010). Particle markov chain monte carlo methods. Journal of the Royal Statistical Society: Series B (Statistical Methodology), 72(3), 269-342.

Arocena, P., Saal, D. S., Urakami, T., \& Zschille, M. (2020). Measuring and decomposing productivity change in the presence of mergers. European Journal of Operational Research, 282(1), 319-333.

Badinelli, R. D. (1996). Approximating probability density functions and their convolutions using orthogonal polynomials. European Journal of Operational Research, 95(1), 211-230.

Bai, J., Jin, W., \& Serfling, M. (2021). Management practices and mergers and acquisitions. Management Science.

Bloom, N., \& Van Reenen, J. (2007). Measuring and explaining management practices across firms and countries. The Quarterly Journal of Economics, 122(4), 1351-1408.

Bloom, N., \& Van Reenen, J. (2010). Why do management practices differ across firms and countries?. Journal of Economic Perspectives, 24(1), 203-24.

Bloom, N., Sadun, R., \& Van Reenen, J. (2017). Management as a Technology? (No. w22327). National Bureau of Economic Research.

Bonin, J. P., Hasan, I., \&Wachtel, P. (2005). Bank performance, efficiency and ownership in transition countries. Journal of Banking \& Finance, 29(1), 31-53.

Bonsall IV, S. B., Holzman, E. R., \& Miller, B. P. (2017). Managerial ability and credit risk assessment. Management Science, 63(5), 1425-1449.

Bruhn, M., Karlan, D., \& Schoar, A. (2010). What capital is missing in developing countries?. American Economic Review, 100(2), 629-33.

Chang, W. J., Hayes, R. M., \& Hillegeist, S. A. (2016). Financial distress risk and new CEO compensation. Management Science, 62(2), 479-501.

Chopin, N., \& Singh, S. S. (2015). On particle Gibbs sampling. Bernoulli, 21(3), 1855-1883.

Cameron, A. C., \& Trivedi, P. K. (2013). Regression analysis of count data (Vol. 53). Cambridge university.

Chen, P., Xu, H., Zou, X. (2017). The effects and incentive of vertical mergers: An analysis from the view of OM. European Journal of Operational Research, 263 (1),158-172. 
Chu, C. W., \& Zhang, G. P. (2003). A comparative study of linear and nonlinear models for aggregate retail sales forecasting. International Journal of Production Economics, 86(3), 217-231.

Creal, D. (2012). A survey of sequential Monte Carlo methods for economics and finance. Econometric Reviews, 31(3), 245-296.

Creal, D. D., \& Tsay, R. S. (2015). High dimensional dynamic stochastic copula models. Journal of Econometrics, 189(2), 335-345.

Custódio, C., Ferreira, M. A., \& Matos, P. (2013). Generalists versus specialists: Lifetime work experience and chief executive officer pay. Journal of Financial Economics, 108(2), 471-492.

Delis, M. D., Iosifidi, M., \& Tsionas, M. (2020). Management estimation in banking. European Journal of Operational Research, 284(1), 355-372.

Delis, M. D., Iosifidi, M., Kazakis, P., Ongena, S., \& Tsionas, M. G. (2021). Management practices and M\&A success (No. 20-102). Swiss Finance Institute.

Delis, M. D., \& Tsionas, M. G. (2018). Measuring management practices. International Journal of Production Economics, 199, 65-77.

Demerjian, P., Lev, B., \& McVay, S. (2012). Quantifying managerial ability: A new measure and validity tests. Management Science, 58(7), 1229-1248.

Deming, W. E., \& Edwards, D. W. (1982). Quality, productivity, and competitive position (Vol. 183). Cambridge, MA: Massachusetts Institute of Technology, Center for advanced engineering study.

Eubank, R. L., \& Speckman, P. (1990). Curve fitting by polynomial-trigonometric regression. Biometrika, 77(1), 1-9.

Falato, A., Li, D., \&Milbourn, T. (2015). Which skills matter in the market for CEOs? Evidence from pay for CEO credentials. Management Science, 61(12), 2845-2869.

Flynn, B. B., Schroeder, R. G., \& Sakakibara, S. (1994). A framework for quality management research and an associated measurement instrument. Journal of Operations Management, 11(4), 339-366.

Fuller, K., Netter, J., \& Stegemoller, M. (2002). What do returns to acquiring firms tell us? Evidence from firms that make many acquisitions. The Journal of Finance, 57(4), 1763-1793.

Gabaix, X., \&Landier, A. (2008). Why has CEO pay increased so much?. The Quarterly Journal of Economics, 123(1), 49-100.

Gantchev, N., Sevilir, M., \& Shivdasani, A. (2020). Activism and empire building. Journal of Financial Economics, 138(2), 526-548.

Gelfand, A. E., Hills, S. E., Racine-Poon, A., \& Smith, A. F. (1990). Illustration of Bayesian inference in normal data models using Gibbs sampling. Journal of the American Statistical Association, 85(412), 972-985. 
Geweke, J. (1992). Evaluating the accuracy of sampling-based approaches to the calculations of posterior moments. Bayesian Statistics, 4, 641-649.

Godsill, S. J., Doucet, A., \& West, M. (2004). Monte Carlo smoothing for nonlinear time series. Journal of the American Statistical Association, 99(465), 156-168.

Golubov, A., Yawson, A., \& Zhang, H. (2015). Extraordinary acquirers. Journal of Financial Economics, 116(2), 314-330.

Goodfellow, I., Bengio, Y., Courville, A., \& Bengio, Y. (2016). Deep learning (Vol. 1, No. 2). Cambridge: MIT press.

Greene, W. H. (2008). The econometric approach to efficiency analysis. The measurement of productive efficiency and productivity growth, 1(1), 92-250.

Hambrick, D. C., \& Mason, P. A. (1984). Upper echelons: The organization as a reflection of its top managers. Academy of Management Review, 9(2), 193-206.

Hendricks, K. B., \& Singhal, V. R. (1997). Does implementing an effective TQM program actually improve operating performance? Empirical evidence from firms that have won quality awards. Management Science, 43(9), 1258-1274.

Hendricks, K. B., \& Singhal, V. R. (2001). The long-run stock price performance of firms with effective TQM programs. Management Science, 47(3), 359-368.

Hietschold, N., Reinhardt, R., Gurtner, S., 2014. Measuring critical success factors of TQM implementation successfully - a systematic literature review. International Journal of Production Research 52:21, 6254-6272.

Kaplan, D., \& Depaoli, S. (2012). Bayesian structural equation modeling. In R. Hoyle (Ed.), Handbook of structural equation modeling (pp. 650-673). New York, NY: Guilford Press.

Katz, R. L. (1974). Skills of an effective administrator. Harvard Business Review Press.

Koester, A., Shevlin, T., \& Wangerin, D. (2017). The role of managerial ability in corporate tax avoidance. Management Science, 63(10), 3285-3310.

Lucas Jr, R. E. (1978). On the size distribution of business firms. The Bell Journal of Economics, 508-523.

Miller, D. (1991). Stale in the saddle: CEO tenure and the match between organization and environment. Management Science, 37(1), 34-52.

Murphy, K. J., \& Zabojnik, J. (2007). Managerial capital and the market for CEOs. Available at SSRN 984376.

Nevo, A. (2001). Measuring market power in the ready-to-eat cereal industry. Econometrica, 69(2), 307342.

Pasiouras, F. (2013). Efficiency and productivity growth: modelling in the financial services industry. John Wiley \& Sons. 
Powell, T. C. (1995). Total quality management as competitive advantage: a review and empirical study. Strategic Management Journal, 16(1), 15-37.

Prajogo, D. I., \& Sohal, A. S. (2006). The relationship between organization strategy, total quality management (TQM), and organization performance - the mediating role of TQM. European Journal of Operational Research, 168(1), 35-50.

Prybutok, V. R., \& Ramasesh, R. (2005). An action-research based instrument for monitoring continuous quality improvement. European Journal of Operational Research, 166(2), 293-309.

Qin, X. S., Huang, G. H., Zeng, G. M., Chakma, A., \& Huang, Y. F. (2007). An interval-parameter fuzzy nonlinear optimization model for stream water quality management under uncertainty. European Journal of Operational Research, 180(3), 1331-1357.

Soteriou, A., \& Zenios, S. A. (1999). Operations, quality, and profitability in the provision of banking services. Management Science, 45(9), 1221-1238.

StataCorp. 2017. Stata Statistical Software: Release 15. College Station, TX: StataCorp LLC.

Sueyoshi, T. (1994). Stochastic frontier production analysis: Measuring performance of public telecommunications in 24 OECD countries. European Journal of Operational Research, 74(3), 466478.

Tabak, B. M., \& Tecles, P. L. (2010). Estimating a Bayesian stochastic frontier for the Indian banking system. International Journal of Production Economics, 125(1), 96-110.

Tarí, J. J., Molina, J. F., \& Castejon, J. L. (2007). The relationship between quality management practices and their effects on quality outcomes. European Journal of Operational Research, 183(2), 483-501.

Van de Schoot, R., Kaplan, D., Denissen, J., Asendorpf, J. B., Neyer, F. J., \& Van Aken, M. A. (2014). A gentle introduction to Bayesian analysis: Applications to developmental research. Child Development, 85(3), 842-860.

Whiteley, N. (2010). Discussion on particle Markov chain Monte Carlo methods. Journal of the Royal Statistical Society: Series B, 72(3), 306-307.

Wu, D. D., Zhou, Z., \& Birge, J. R. (2011). Estimation of potential gains from mergers in multiple periods: a comparison of stochastic frontier analysis and Data Envelopment Analysis. Annals of Operations Research, 186(1), 357-381. 